\title{
Screening, Characterization and Identification of Probiotic Potential LAB with Phytase Activity
}

\author{
R.M. Dhingani*, B.H. Joshi and R.V. Prasad \\ Department of Food Quality Assurance, College of Food Processing Technology and \\ Bio-Energy, Anand Agricultural University, Anand-388110, India \\ *Corresponding author
}

\author{
A B S T R A C T
}

\section{Keywords}

LAB, Bile salt, Probiotics, Phytase and $16 \mathrm{~S}$ rRNA.

Article Info

Accepted:

10 July 2017

Available Online:

10 September 2017
Probiotics have been extensively studied and explored commercially in many different products in the world. Looking to the demand and health prospects extensive screening for Lactic Acid Bacteria (LAB) with probiotic potentials was investigated. Total 57 bacterial isolates were collected from the 32 samples. Out of which, 33 LAB isolates were confirmed on the basis of morphological and preliminary biochemical characterization. On the basis of probiotic traits such as low $\mathrm{pH}$ and high bile salt tolerance, 8 LAB isolates with probiotic potentials were selected. These were further evaluated for phytase activity which is very important for availing various minerals and proteins in the gut. Two LAB isolates found to show significant phytase activity. Considering the probiotic potential along with phytase activity these isolates show health prospects and therefore they were characterized for identification. Morphological, biochemical and molecular characterization studies revealed Isolate 21 as strain of Pediococcus acidilactici (KU173544) and Isolate 24 (KU173545) as a strain of Pediococcus lolii.

\section{Introduction}

According to world health organization probiotics defined as "live microorganisms which when administered in adequate amounts confer a health benefit on the host". There is growing evidence for their efficacy in protecting against acute diarrhoeal disease in children, gastroenteritis and antibioticassociated diarrhoea, inflammatory bowel diseases and pouchitis (Reid et al., 2003; Geier et al., 2007; Nomoto K., 2005; Weng and Walker, 2006). There is also evidence to support further investigation of the use of probiotics and prebiotics in the treatment of illnesses affecting sites other than the intestinal tract, e.g. urinary tract infections, vaginal infections, arthritis, atopic eczema, pharyngitis and otitis media (Reid et al., 2003; Geier et al., 2007; Tagg and Dierksen, 2003; Lenoir et al., 2007). The numerous perceived health benefits and the growing awareness about probiotics have caught the attention of the food industry (Saarela et al., 2002; Salminen and Gueimonde, 2004). Food companies are increasingly manufacturing foods with incorporated probiotic bacteria, which fall under the new category of foods so called functional foods. Probiotic dairy products such as yogurts containing L. acidophilus and Bifidobacterium spp. constitute a significant 
amount among the commercially available probiotic foods (Reid et. al., 2003). The goal of functional foods is to improve the quality of life, enhance health status and increase lifespan while maintain health preventing diseases.

Besides imparting all these beneficial attributes probiotics are also known to produce various enzymes that help in the digestion of monogastric animals, phytases and lipases being the important ones. Phytic acid (myo-inositol hexakis phosphate, phytate) is the major storage form of phosphorus in cereals, oil and legumes (Khattak et al., 2006). Phytase, a specific group of phosphatase, hydrolyses phytic acid to myo-inositol and phosphoric acid. In the context of human and animal nutrition, two aspects of phytate are critically important (Reddy et al. 1982; Wodzinski and Ullah, 1996): (i)monogastric animals have only low levels of phytate-degrading enzymes in their digestive tracts, and since phytic acid itself is not absorbed. (ii) phytic acid is considered to be an anti-nutrient factor as it forms complexes with proteins and a variety of metal ions and therefore decreases the dietary availability of these nutrients. Because of these problems, there is considerable interest in phytate-degrading enzymes. Inorganic phosphate is therefore added to their diet to meet the phosphorus requirement, while undigested phytate phosphorus is excreted in manure and poses a serious phosphorus pollution problem, contributing to the eutrophication of surface water in areas of intensive livestock production (Bajaj and Wani, 2011). The formation of insoluble mineral-phytate complexes at physiological $\mathrm{pH}$ values is regarded as the major reason for the poor mineral bioavailability, because these complexes are essentially non absorbable from the human gastrointestinal tract (Greiner and Konietzny, 2006). Minerals are involved in activation of intracellular and extracellular enzymes, in regulation of critical $\mathrm{pH}$ levels in body fluids necessary for the control of metabolic reactions and in osmotic balance between the cell and its environment. A deficiency of any one of the essential minerals can result in severe metabolic disorders and compromise the health of the organism. Some minerals deficiencies are common in developing countries, but mineral sub-deficiencies may also occur in developed countries (Lopez et al., 2002).

The objectives of present studies were to isolate and identify phytase producing probiotic potential LABs for its exploitation for better health prospects.

\section{Materials and Methods}

\section{Isolation and purification of LABs}

Idli batter and infant stool samples were collected from the different idli vendors and Gynaecology Hospitals from the nearby region of Anand. MRS agar medium was used for the selective isolation of LAB. Pour plate technique was used for the isolation of LAB from the idli batter and infant stool sample. Isolated colonies were purified by subcultured on MRS agar plate for 2-3 times.

\section{Morphological and preliminary biochemical characterization of LABs}

Morphological and biochemical characteristics such as Gram staining, spore staining, capsule staining and catalase test were studied by following Bergey's manual of systematic bacteriology (Kandler, 1986).

\section{Screening for probiotic potential isolates}

\section{Acid tolerance study}

LAB isolates were evaluated for acid tolerance study. Each isolates were activated 
by incubating in MRS broth for $24 \mathrm{hrs}$. at $37^{\circ} \mathrm{C}$. This activated culture was inoculated into MRS broth having different $\mathrm{pH}(1.5,2$, 2.5, 3 and 3.5). The inoculated broths were incubated at $37^{\circ} \mathrm{C}$ for $24 \mathrm{hrs}$. Then the growth was measured using a spectrophotometer at $620 \mathrm{~nm}$ (Hoque et al., 2010).

\section{Bile salt tolerance study}

Further LABs were also studied for its bile salt tolerance. Overnight grown culture was inoculated into MRS broth having different bile salt concentrations $(0.2 \%, 0.4 \%, 0.6 \%$, $0.8 \%$ and $1.0 \%$ ). The inoculated broths were incubated at $37^{\circ} \mathrm{C}$ for $24 \mathrm{hrs}$ and the growth was measured using a spectrophotometer at $620 \mathrm{~nm}$ (Hoque et al., 2010).

\section{Phytase activity}

Selected low $\mathrm{pH}$ resistant and high bile salt tolerant LAB isolates were grown in MRS basal modified medium according to de Man et al. (1960) to evaluate their phytase activity. Then, these activated isolate inoculated on phytate-MRS agar plate and zone of clearance of phytate was observed around the colony of phytase producer. To eliminate false positive results, petridish flooded with cobalt chloride and ammonium molybdate solution sequentially and finally it was removed and examined for zones of phytate hydrolysis (Melis Sumengen et al., 2012). Quantitative phytase production from the potential LAB isolates were also studied. Phytase activity from cell extract (crude enzyme) of selected isolate was assayed by determining the amount of inorganic phosphate released from sodium phytate incubated with crude enzyme in phytase reaction buffer. It was measured by incubating $1 \mathrm{ml}$ of crude enzyme solution with $200 \mu \mathrm{l}$ of $10 \mathrm{mM}$ sodium phytate as a substrate and $200 \mu \mathrm{l}$ of $0.2 \mathrm{M}$ sodium acetate buffer ( $\mathrm{pH}$ 5.5). The mixture was raise up to 2 $\mathrm{ml}$ with sterile distilled water and the solution was incubated at $37^{\circ} \mathrm{C}$ for $10 \mathrm{~min}$. The reaction was terminated by adding $4 \mathrm{ml}$ of the AAM solution and optical density measured at $410 \mathrm{~nm}$ with a spectrophotometer (Heinonen-Lahti method, 1981).One unit of phytase activity (U) was defined as the amount of enzyme that produces $1 \mu \mathrm{mol}$ of inorganic phosphorous per minute.

\section{Molecular characterization}

Selected two isolates with potential probiotic trait and phytase activity were further identified by molecular characterization. Bacterial DNA was extracted and purified. The $16 \mathrm{~S}$ rDNA was amplified using universal bacterial forward and reverse primers (Maniatis et al., 1982).

Amplicon purified by Gel/PCR DNA Fragment Extraction Kit (Geneaid Biotech Ltd., Taipei, Taiwan) was directly sequenced by ABI PrismTMBigDyeTM terminator cycle sequence ready reaction kit (Applied Biosystems, Stafford, USA) according to manufacturer's instruction.

The resultant sequenced data file (AB1) was processed, trimmed and contig developed by using Chromas and BioEdit software. Developed contig was used for the identification of isolate at their species level by using online BLAST tool of NCBI (http://www.ncbi.nlm.nih.gov/blast). Contig was processed by offline tool (sequin) and resulted sequin processed file submitted to genebank for accession number. Phylogenetic tree was constructed by using online BLAST tool.

\section{Results and Discussion}

\section{Isolation and purification of organisms}

Extensive screening for LAB was done from the stool and idli batter sample. Total 20 of 
idli batter and 12 of infant stool samples were collected and isolation of LAB was carried out. Pour plate method was used for the isolation of LAB using selective MRS agar medium. The isolates were studied thoroughly for characteristics and growth pattern using microscope. Total 57 bacterial isolates were obtained from the 32 samples.

\section{Morphological and preliminary biochemical characterization}

Based on morphological and preliminary biochemical characterization, 33 isolates were found to be catalase negative, non-capsulated, non-spore former Gram positive bacteria. Considering all these typical characteristics of LABs, they were studied further for evaluation of probiotic traits.

\section{Screening of isolates for probiotic potential}

\section{Acid tolerance study}

One of the desired characteristics of probiotic strain is to ability to resist against acidic $\mathrm{pH}$ of the stomach which is around 2. Thus, the effect of $\mathrm{pH}$ ranging from 1.5 to 3.5 on the selected strains was studied. It was found that most of the strain cannot able to survive at 1.5 $\mathrm{pH}$. Approximately $50 \%$ of the isolates can able to resist $2 \mathrm{pH}$.The isolates from idli batter showed higher acid tolerance as compare to stool isolates. Total 33 isolates were evaluated for its acid tolerance study. Out of them, 14 isolates were found to tolerate up to $2 \mathrm{pH}$ and therefore selected for further studies (Fig. 1).

\section{Bile salt tolerance study}

Besides strong acid tolerance ability, probiotic microorganisms have to defend higher bile salt concentration in gastrointestinal tract. Hence, bile tolerance is considered to be one of the important properties required for better survival and as a consequence for a probiotic activity. Selected isolates from the acid tolerance study were further scrutinized for bile salt tolerance. In this study MRS broth supplemented with bile salts in the range of 0.2 to $1.0 \%$ concentration was used to grow selected isolates. Out of them 14 isolates, 8 isolates were found to resist bile salt up to $1.0 \%$ concentration (Fig. 2 ). Considering the acid tolerance and bile salt tolerance which is the pre requisite for any probiotics, these isolates found to be potential and therefore further studied for phytase production ability.

Fig.1 Acid tolerance profile of selected LABl isolates

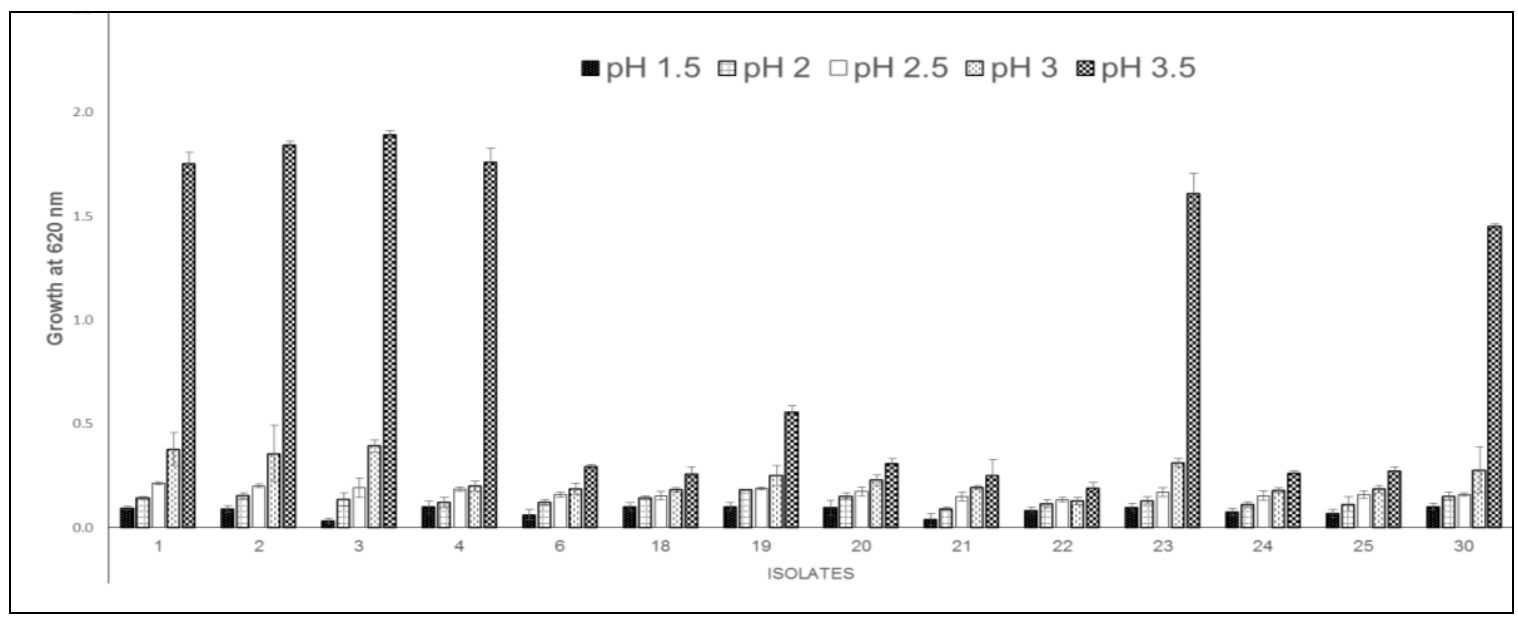


Fig.2 Bile salt tolerance study of selected isolates

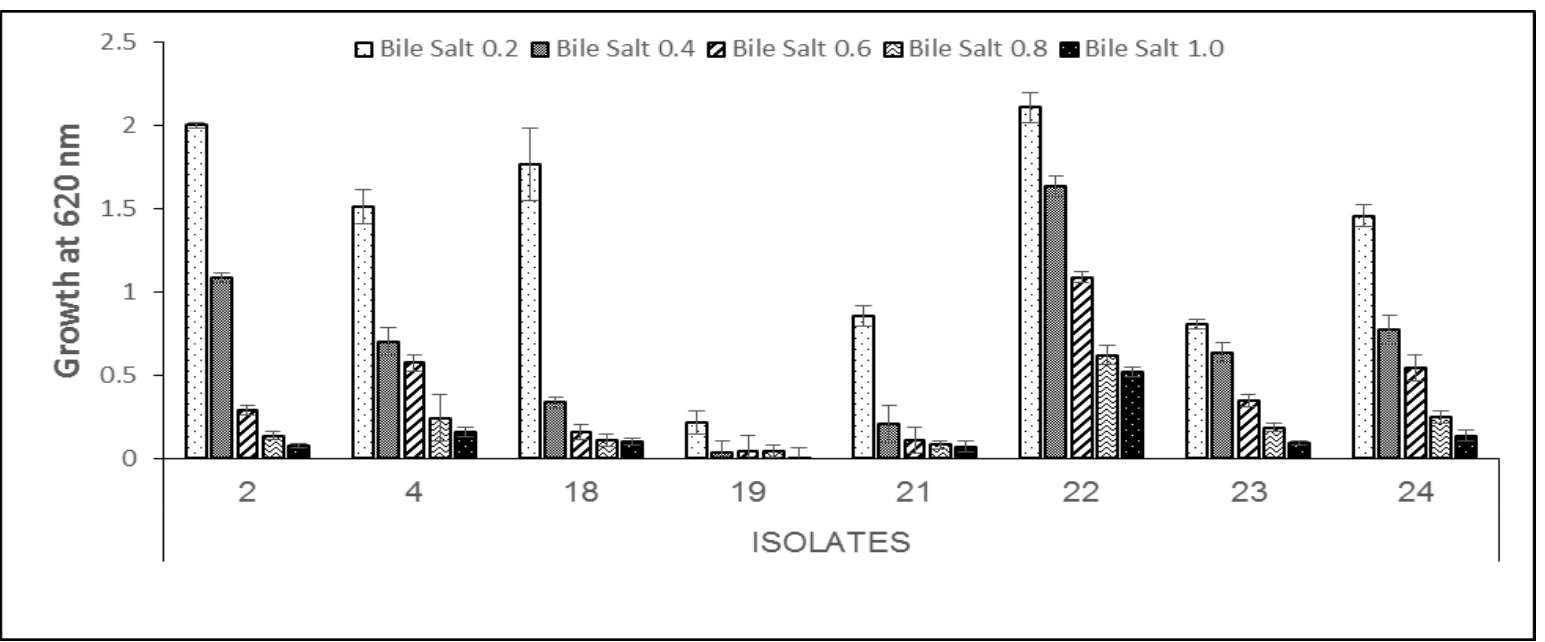

Fig.3 Phytase enzyme activity (U/ml) of Isolates 21 and 24

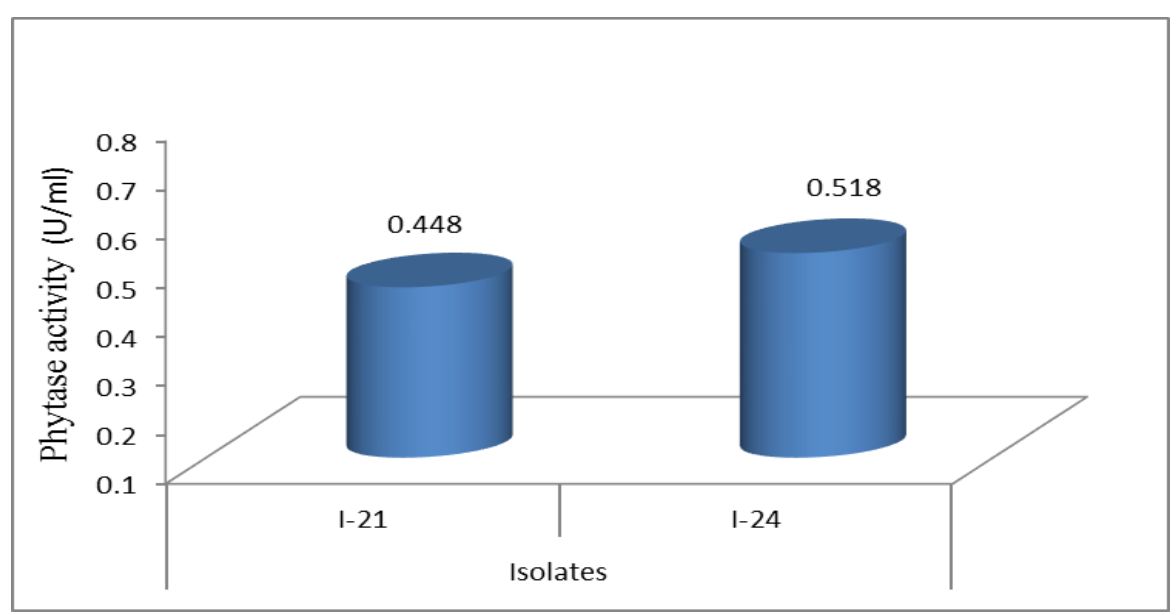

Fig.4 Distance tree of query sequence (Pediococcus acidilactici IB01) with available reference sequence in slanted cladogram form

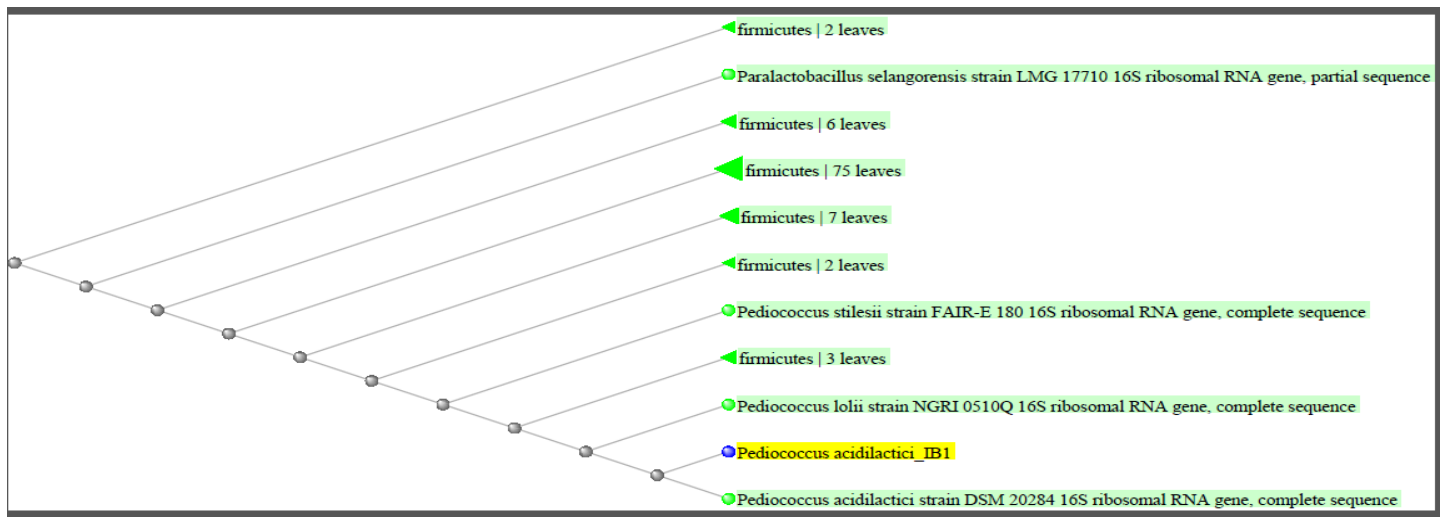


Fig.5 Distance tree of query sequence (Pediococcus lolii IB02) with available reference sequence in circular layout

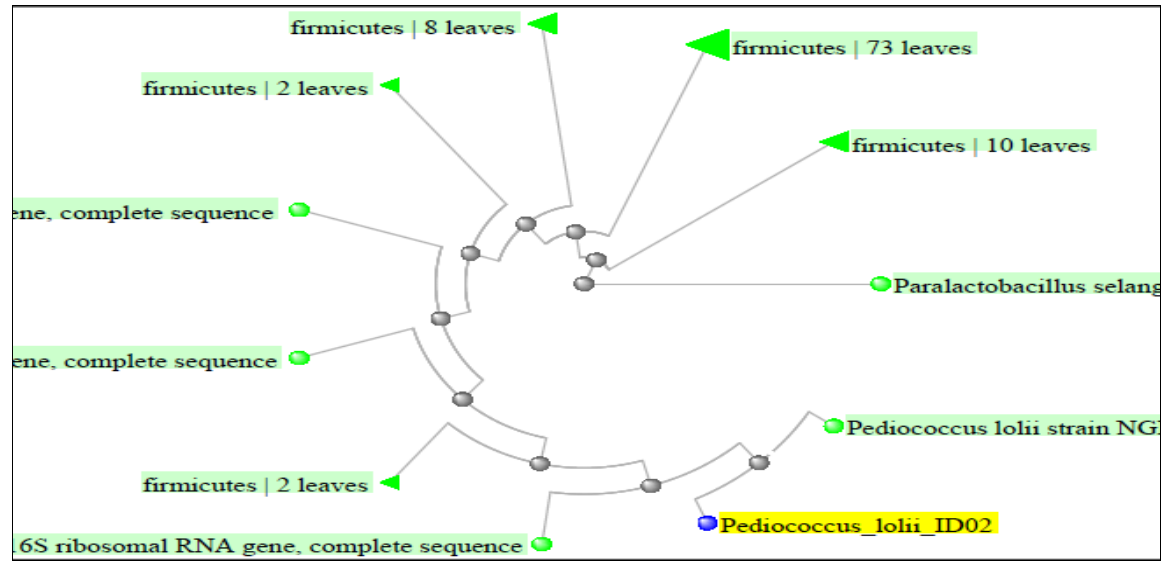

\section{Phytase activity study}

Selected eight LAB were evaluated for phytase production qualitatively and quantitatively. Out of the eight isolates, isolate 21 and isolate 24 were found to show zone of clearance in phytase plate assay. Remaining all the isolates were not able to produce phytase. Upon quantification of phytase enzyme, isolate 21 and 24 were found to produce $0.448 \mathrm{U} / \mathrm{ml}$ and 0.518 $\mathrm{U} / \mathrm{ml}$ respectively (Fig. 3).

\section{Molecular characterization of scrutinized isolates}

Selected isolates 21 and 24 were found to be shown potential probiotic traits with significant phytase productivity. Considering this prospects both isolates were further investigated for their identification using molecular characterization of 16 sRNA. The forward and reverse sequencing data files (AB1) of this selected isolates were generated. Contig of 1117 nucleotides (I-21) and 1461 nucleotides (I-24) were developedwith the help ofChromas and BioEdit software. By using online BLAST tool of NCBI, isolate 21 has shown maximum similarity with Pediococcus acidilactici and isolate 24 with Pediococcus lolii. Sequin processed file of Pediococcus acidilactici and Pediococcus lolii were submitted in Genebank. Accession no. KU173544 and KU173545 allotted by the Genebank for Pediococcus acidilactici and Pediococcus lolii respectively. Further phylogenetic relation of Pediococcus acidilactici and Pediococcus lolii with the other available sequenced genotypes is shown below in form of tree dendogram (Figs. 4 and $5)$.

In conclusion, total of 57 bacterial isolates were obtained from the 32 samples. Out of these, 33 LABs were selected based on morphological and preliminary biochemical characterization. These 33 LAB isolates where further scrutinized base on the $\mathrm{pH}$ and bile salt tolerance study reveals 8 isolates as potential candidate for probiotics. These selected isolates were investigated for phytase activity. Results showed isolate 21 and 24 are phytase producer and therefore were identified by $16 \mathrm{~S}$ rRNA sequencing. Isolate 21 was identified as a newly isolated strain of Pediococcus acidilactici (KU173544) and Isolate 24 (KU173545) as a Pediococcus lolii. Prospective features of probiotic with phytase activity shown by these newly investigated isolated have also GRAS status could be explored further as probiotics.

\section{References}

Bajaj BK, Wani MA (2011). Enhanced phytase production from Nocardia sp. MB 36 using agro-residues as substrates: 
Potential application for animal feed production. Eng. Life. Sci. 11: 620-628.

de Man JC, Rogosa M, Sharpe E (1960). A medium for the cultivation of lactobacilli. J. Appl. Bacteriol. 23, 130-135.

Geier MS, Butler RN, Howarth GS (2007). Inflammatory bowel disease: current insights into pathogenesis and new therapeutic options; probiotics, prebiotics and synbiotics. Int. J. Food. Microbiol. 115: 1-11.

Greiner R, Konietzny U (2006). Phytase for food application. Food. Technol. Biotechnol., 44, 125- 140.

Heinonen JK, Lahti RJ (1981). A new and convenient colorimetric determination of inorganic ortho- phosphate and its application to the assay of inorganic pyrophosphatase. Anal. Biochem. 113, 313-317.

Hoque MZ, Akter F, Hossain KM, Rahman MSM, Billah MM, Islam KMD (2010). Isolation, identification and analysis of probiotic properties of lactobacillus Spp. from selective regional yoghurts. World. J. Dairy. Food. Sci. 5 (1): 39-46.

Kandler O, Weiss N (1986). Regular, nonsporing Gram-positive rods: Bergey's Manual of Systematic Bacteriology. P.H.A Sneath, N. Mair, M.E. Sharpe and J.G. Holt. Williams and Wilkins, Baltimore. 2: 1208-1234.

Khattak FM, Pasha TN, Hayat Z, Mahmud A (2006). Enzymes in poultry nutrition. J. Anim. Pl. Sci. 16(1-2):1-7.

Lenoir-Wijnkoop I et al., (2007). Probiotic and prebiotic influence beyond the intestinal tract. Nutr. Rev. 65: 469-89.

Lopez A, Xamena N, Marcos R, Velazquez A (2002). Germ cells microsatellite instability. The effect of different mutagens in a mismatch repair mutant of
Drosophila (spel1). Mutat. Res.514(1-2): 87-94.

Maniatis T, Fritsch EF, Sambrook J (1982). Molecular cloning: a laboratory manual. USA: Cold spring harbor laboratory.

Melis Sumengen, Sadik Dincer, Aysenur Kaya (2012). Phytase production from Lactobacillus brevis. Turk. J. Biol. 36; 533-541.

Morishita T, Deguchi Y, Yajima M, Sakurai T, Yura T (1981). Multiple nutritional requirements of lactobacilli: genetic lesions affecting aminoacids biosynthetic pathways. J. Bacteriol. 148, 64-71.

Nomoto K (2005). Prevention of infections by probiotics. J. Biosci. Bioeng. 100: 58392.

Reddy NR, Sathe SK, Salunkhe DK (1982). Phytates in legumes and cereals. Adv. Food. Res. 28: 1-92.

Reid G, Jass J, Sebulsky MT, McCormick JK (2003). Potential uses of probiotics in clinical practice. Clin. Microbiol. Rev., 16: 658-672.

Saarela M, Mogensen G, Fonden R, Matto J, Mattila-Sandholm T (2000). Probiotic bacteria: safety, functional and technological properties. J. Biotechnol. $84,197-215$.

Salminen S, Gueimonde M (2004). Human studies on probiotics: What is scientifically proven? J. Food. Sci. 69: M137-M140

Tagg JR, Dierksen KP (2003). Bacterial replacement therapy: adapting 'germ warfare' to infection prevention. Trends. Biotechnol. 21: 217-23.

Weng MQ, Walker WA (2006). Bacterial colonization, probiotics, and clinical disease. J. Pediatr. 149: S107-14.

Wodzinski RJ. Ullah AHJ (1996). Phytase. Adv. Appl. Microbiol., 42, 263-302.

\section{How to cite this article:}

Dhingani, R.M., B.H. Joshi and Prasad, R.V. 2017. Screening, Characterization and Identification of Probiotic Potential LAB with Phytase Activity. Int.J.Curr.Microbiol.App.Sci. 6(9): 3539-3545. doi: https://doi.org/10.20546/ijcmas.2017.609.435 